\title{
The effect of omeprazole on the development of experimental autoimmune encephalomyelitis in C57BL/6J and SJL/J mice
}

\author{
Scott A Sands', Sheila Tsau', Thomas M Yankee², Brooks L Parker², Aaron C Ericsson ${ }^{3}$ and Steven M LeVine ${ }^{1 *}$
}

\begin{abstract}
Background: Gastric disturbances such as dyspepsia are routinely encountered by multiple sclerosis (MS) patients, and these conditions are often treated with gastric acid suppressors such as proton pump inhibitors, histamine $\mathrm{H} 2$ receptor antagonists, or antacids. The proton pump inhibitor omeprazole can alter the gut flora and immune responses, both of which can influence the course of experimental autoimmune encephalomyelitis (EAE), an animal model of MS. The objective of the current study was to examine the effect of omeprazole treatment on the development of EAE. Bacterial microbiome analysis of mouse fecal pellets was determined in C57BL/6J EAE mice chronically treated with omeprazole, and spleen immune cell content, clinical scores, weight, rotarod latency, and histopathology were used as outcome measures in C57BL/6J and SJL/J mice with EAE.

Results: Omeprazole treatment resulted in decreases in Akkermansia muciniphila and Coprococcus sp. and an increase in unidentified bacteria in the family S24-7 (order Bacteroidales) in C57BL/6J mice with EAE. Omeprazole did not alter spleen immune cell content compared to vehicle in EAE mice, but differences independent of treatment were observed in subsets of T cells between early and advanced disease in C57BL/6J mice as well as between the two strains of mice at an advanced disease stage. Omeprazole caused no difference in clinical scores in either strain, but significantly lowered weight gain compared to vehicle in the C57BL/6J mice with EAE. Omeprazole also did not alter rotarod behavior or hindbrain inflammatory cell infiltration compared to vehicle in both strains of mice with EAE. Rotarod latency did reveal a negative correlation with clinical scores during active disease in both mouse strains, but not during clinical remission in SJL/J mice, suggesting that rotarod can detect disability not reflected in the clinical scores.

Conclusions: Despite alterations in the gut microbiota and weight gain in the C57BL/6J EAE model, omeprazole had no effect on multiple measures of disease activity in C57BL/6J and SJL/J mice with EAE, supporting the notion that omeprazole does not substantially influence disease activity in MS patients.
\end{abstract}

Keywords: Akkermansia muciniphila, Bacteroidales, Coprococcus, Multiple sclerosis, Proton pump inhibitor, T cells

\section{Background}

Gastric disturbances are commonly encountered in multiple sclerosis (MS) patients, with $\sim 30 \%$ reporting problems with dyspepsia [1]. Many of these disturbances are treated with gastric acid suppressors such as proton pump inhibitors (PPI), histamine $\mathrm{H} 2$ receptor antagonists, or antacids. These gastric acid suppressors are widely used, available over the counter, and generally

\footnotetext{
* Correspondence: slevine@kumc.edu

${ }^{1}$ Department of Molecular and Integrative Physiology, University of Kansas Medical Center, 3901 Rainbow Blvd, Kansas City 66160, KS, USA

Full list of author information is available at the end of the article
}

considered safe; however, there have been concerns about susceptibility to small intestinal bacterial overgrowth [2] and enteric infections [3]. Since the gut microflora has been shown to influence the disease course in experimental autoimmune encephalomyelitis (EAE) [4-6], an animal model of MS, a PPI could theoretically impact disease progression by altering the microbiota. In addition, PPIs can directly affect the immune response [7], raising the possibility of a second mechanism of action by PPIs on disease progression. The objective of this study was to evaluate the effect of omeprazole treatment on the development of EAE in the C57BL/6J 
model of progressive MS and the SJL/J model of relapsingremitting MS.

\section{Methods}

\section{Animal handling and housing}

All studies involving the use of animals were approved by the Institutional Animal Care and Use Committee of the University of Kansas Medical Center. Female C57BL/6J and female SJL/J mice (Jackson Laboratory, Bar Harbor, ME) were used for EAE induction. Animals were maintained on standard rodent chow (8604 Teklad rodent diet, Harlan, Indianapolis, IN), had water available ad libitum, and were maintained on a $12 / 12 \mathrm{~h}$ light/dark cycle. C57BL/6J mice were given 31M Nutrigel (ClearH2O, Portland, ME) supplementation as mice started to develop advanced disease, with all mice on Nutrigel by Day 27 post-encephalitogen injection. SJL/J mice that developed advanced disease, and their cage mates, received supplementation with DietGel Recovery Nutrigel (ClearH2O).

\section{EAE induction - C57BL/6J mice}

EAE was induced in $\sim 5$ week old C57BL/6J female mice (Jackson Laboratory). Two studies were conducted; the first study lasted until Day 18 post-encephalitogen, the point at which disease was first detected (early clinical), while the second study lasted until Day 46 postencephalitogen, at which point most mice were in an active disease stage of EAE, i.e., clinical disability. For both studies, mice were anesthetized with isoflurane (Abbott Labs, North Chicago, IL), dorsal surface shaved, and given two subcutaneous injections (dorsum) of the encephalitogen myelin oligodendrocyte glycoprotein peptide [amino acids $35-50 ; 250 \mu \mathrm{g}$ ( $1^{\text {st }}$ study) or $300 \mu \mathrm{g}$ $\left(2^{\text {nd }}\right.$ study)] with emulsion [Freund's incomplete adjuvant containing $250 \mu \mathrm{g}$ ( $1^{\text {st }}$ study) or $500 \mu \mathrm{g}$ ( $2^{\text {nd }}$ study) Mycobacterium tuberculosis (Difco Laboratories, Detroit, MI)]. Once completed, an intraperitoneal (i.p.) injection of pertussis toxin (PTX; $100 \mathrm{ng} / 100 \mu \mathrm{l}$ saline; List Biological Laboratories, Campbell, CA) was administered. Mice were given one ( $1^{\text {st }}$ study- Day 3 post-encephalitogen injection) or two $\left(2^{\text {nd }}\right.$ study- Day 3 and 7 post-encephalitogen injection) additional PTX injections. Mice were weighed on Day 0 and 7 post-encephalitogen, and every day thereafter, and scoring began on Day 9 post-encephalitogen. Mice were scored using a modified $0-8$ point scale from that described previously [8]. A 0-8 point scale offers greater sensitivity to detect statistical differences between groups compared to 0-5 scales, or has a similar sensitivity to 0-5 scales that include some half point differences. Briefly, the scoring system was as follows: $0=$ normal; $1=$ flaccid/limp tail; 2 = hindlimb weakness causing righting difficulty from a supine position; $3=$ hindlimb weakness causing righting inability $\geq 8 \mathrm{sec}$ from a supine position; $4=$ hindlimb weakness causing limping and abnormal gait; $5=$ partial (one limb) hindlimb paralysis or extensive hindlimb weakness such that the hindlimbs cannot contribute to mobility; $6=$ total (both) hindlimb paralysis plus forelimb weakness; $7=$ hindlimb paralysis and forelimb weakness or paralysis resulting in a side resting position; $8=$ moribund requiring sacrifice or inadvertent death. Omeprazole (Premier Pharmacy Labs, Weeki Wachee, FL) $(15 \mathrm{mg} / \mathrm{kg}$, i.p., twice daily) and saline administration began on Day 8 postencephalitogen. Spleens were harvested in both studies for flow cytometry. Fecal pellets for bacterial analyses were collected in the $2^{\text {nd }}$ study on Day 40 post-encephalitogen injection. Hindbrains were immersion-fixed in $10 \%$ neutral buffered formalin (Fisher Scientific, Hanover Park, IL) and paraffin-embedded.

\section{EAE induction - SJL/J mice}

EAE was induced in 5-6 week old SJL/J female mice (Jackson Laboratory). Mice were anesthetized with isoflurane (Abbott Laboratories), dorsal surface shaved, and given two subcutaneous injections (dorsum) of encephalitogen [150 $\mu \mathrm{g}$ proteolipid protein peptide (amino acids 139-151)] with emulsion [Freund's incomplete adjuvant containing $250 \mu \mathrm{g}$ M. tuberculosis (Difco Laboratories)]. This was followed with an i.p. injection of PTX. Mice were also administered PTX on Day 3 post-encephalitogen injection.

Mice were weighed at Day 0 and 7 post-encephalitogen administration and every day thereafter. Clinical scoring was performed as described previously [8] except the standard for a score of 5 described above was used. Administration of omeprazole ( $15 \mathrm{mg} / \mathrm{kg}$, i.p., twice daily) or saline began when a score of 1 was first detected (beginning of active disease) and continued until sacrifice. On Day 15 post-encephalitogen injection, which was a peak of disease activity, a matched subset of 5 mice within each group was sacrificed and hindbrains and spleens harvested for histopathology and flow cytometry, respectively. The remaining mice were sacrificed on Day 22 or later post-encephalitogen injection.

\section{Bacterial analysis \\ Sample collection \& DNA extraction}

On Day 40 post-encephalitogen, two freshly evacuated fecal pellets were collected per C57BL/6J mouse with EAE given omeprazole or saline. Pellets were placed into a microcentrifuge tube and immediately frozen on dry ice. Microbiome analysis was performed by the Mutant Mouse Regional Resource Center (University of MissouriColumbia) where the pellets were transferred to $2 \mathrm{~mL}$ round-bottom tubes containing $800 \mu \mathrm{L}$ lysis buffer (500 mM NaCl, $50 \mathrm{mM}$ Tris- $\mathrm{HCl}, 50 \mathrm{mM}$ EDTA, and $4 \%$ sodium dodecyl sulfate) and a $0.5 \mathrm{~cm}$ diameter stainless steel bead. Following mechanical disruption using 
a TissueLyser (Qiagen, Venlo, Netherlands), tubes were incubated at $70^{\circ} \mathrm{C}$ for $20 \mathrm{~min}$ with brief vortexing every $5 \mathrm{~min}$. Samples were then centrifuged at $5000 \times \mathrm{g}$ for $5 \mathrm{~min}$ at room temperature, and the supernatant transferred to a clean $1.5 \mathrm{~mL}$ Eppendorf tube. Ammonium acetate $(10 \mathrm{mM} ; 200 \mu \mathrm{L})$ was added to lysates, mixed thoroughly, incubated on ice for $5 \mathrm{~min}$, and centrifuged at $5000 \times \mathrm{g}$ for $5 \mathrm{~min}$ at room temperature. The supernatant, $750 \mu \mathrm{L}$, was mixed with one volume of chilled isopropanol, mixed thoroughly, incubated on ice for $30 \mathrm{~min}$, and centrifuged at $16000 \times \mathrm{g}$ for $15 \mathrm{~min}$ at $4^{\circ} \mathrm{C}$. The supernatant was aspirated and discarded, and the DNA pellet was washed several times with $70 \% \mathrm{EtOH}$ and resuspended in $150 \mu \mathrm{L}$ of Tris-EDTA. Proteinase-K $(15 \mu \mathrm{L})$ and Buffer AL $(200 \mu \mathrm{L})$ (Qiagen DNeasy kit, Qiagen) were added and incubated at $70^{\circ} \mathrm{C}$ for $10 \mathrm{~min}$, followed by addition of $200 \mu \mathrm{L}$ of $100 \% \mathrm{EtOH}$. The contents of each tube were transferred to a spin column from the DNeasy kit. DNA was purified according to the manufacturer's instructions and eluted in $200 \mu \mathrm{L}$ of EB buffer. Purity of DNA was assessed via spectrophotometry (Nanodrop, Thermo Fisher Scientific, Waltham, MA); yield was determined via fluorometry (Qubit, Life Technologies, Carlsbad, CA) using quant-iT BR dsDNA reagent kit (Invitrogen).

\section{Metagenomic library preparation and sequencing}

Extracted fecal DNA was processed at the University of Missouri DNA Core Facility. Bacterial 16S ribosomal DNA amplicons were constructed by amplification of the V4 hypervariable region of the $16 \mathrm{~S}$ rRNA with primers flanked by Illumina standard adapter sequences. Briefly, universal primers (U515F/806R), previously developed against the V4 region, were used for generating amplicons [9,10]. Oligonucleotide sequences are available at proBase [11]. A single forward primer and reverse primers with a unique 12-base index were used in all reactions. Extracted DNA was quantitated by Qubit fluorometer using the quant-iT HS dsDNA reagent kit (Invitrogen). PCR reactions $(50 \mu \mathrm{L})$ contained $100 \mathrm{ng}$ of genomic DNA, forward and reverse primers $(0.2 \mu \mathrm{M}$ each), dNTPs (200 $\mu \mathrm{M}$ each), and Phusion HighFidelity DNA Polymerase (1U). PCR amplification was performed as follows: $98^{\circ} \mathrm{C}^{(3: 00)}+\left[98^{\circ} \mathrm{C}^{(0: 15)}+50^{\circ} \mathrm{C}^{(0: 30)}+\right.$ $\left.72^{\circ} \mathrm{C}^{(0: 30)}\right] \times 25$ cycles $+72^{\circ} \mathrm{C}^{(7: 00)}$. Amplified product $(5 \mu \mathrm{L})$ from each reaction was combined and thoroughly mixed; pooled amplicons were purified by addition of Axygen AxyPrep MagPCR Clean-up beads $(50 \mu \mathrm{L})$ to an equal volume of $50 \mu \mathrm{L}$ of amplicons and incubated at room temperature for $15 \mathrm{~min}$. Products were washed multiple times with $80 \% \mathrm{EtOH}$ and the dried pellet resuspended in Qiagen EB Buffer $(32.5 \mu \mathrm{L})$, incubated at room temperature for $2 \mathrm{~min}$, and then placed on the magnetic stand for $5 \mathrm{~min}$. Supernatant $(30 \mu \mathrm{L})$ was transferred to low binding microcentrifuge tube for storage. The final amplicon pool was evaluated using the Advanced Analytical Fragment Analyzer automated electrophoresis system, quantified with the Qubit fluorometer using the quant-iT HS dsDNA reagent kit (Invitrogen), and diluted according to Illumina's standard protocol for sequencing on the MiSeq.

\section{Informatics analysis}

Assembly, binning, and annotation of DNA sequences were performed at the MU Informatics Research Core Facility. Briefly, contiguous sequences of DNA were assembled using FLASH software [12], and Qiime v1.7 [13] was used to select representative operational taxonomic units (OTUs). Taxonomy was assigned to selected OTUs using BLAST [14] against the Greengenes database [15] of $16 \mathrm{~S}$ rRNA sequences and taxonomy.

\section{Flow cytometry}

Spleens were minced using a wire mesh, and splenocytes were collected and counted. For the immunodetection of specific populations of $\mathrm{T}$ cells within the spleen, anti-CD4-Pacific Blue, anti-CD8-Alexa647, antiCD24-PE, anti-CD44-PE-Cy5.5, and anti-CD62L-PE-Cy7 were purchased from BioLegend (San Diego, CA) or BD Biosciences (San Jose, CA). Cell labeling was performed in PBS containing 2\% FCS. Flow cytometry studies were performed using a BD LSR II (BD Immunocytometry Systems, San Jose, CA). Data were analyzed using BD FACSDiva software (BD Biosciences). Splenocytes were gated on the live lymphocyte gate and doublet discrimination was performed. Naïve $\mathrm{T}$ cells were defined as $\mathrm{CD} 44^{\text {lo }} \mathrm{CD} 62 \mathrm{~L}^{\text {hi }}$, central memory (CM) $\mathrm{T}$ cells as CD44 ${ }^{\text {hi }}$ CD62L ${ }^{\text {hi }}$, and effector memory (EM) $\mathrm{T}$ cells as CD $44{ }^{\text {hi }}$ CD62L ${ }^{\text {lo }}$.

\section{Rotarod}

The rotarod was set to accelerate from a speed of 4 to 40 rotations per minute in a 300 second time trial. Each mouse was given an exposure trial to familiarize the animal to the task, and this initial trial was not included for data analysis. Each animal was then given two trials and the times at which mice could no longer successfully manage or remain on the rotarod (rotarod latency) were averaged and analyzed for differences between treatment groups and relationships to EAE clinical scores.

\section{Histopathology}

Following paraffin embedding, sagittal sections of the hindbrain were cut at $8 \mu \mathrm{m}$ thickness and processed for hematoxylin and eosin staining. Sections were evaluated on the basis of number of lesions and magnitude of lesions present in the hindbrain. 


\section{Statistics}

The two-tailed Student's t-test was used to evaluate weight change, difference in absolute numbers of subsets of spleen cells, and rotarod latency between omeprazole and saline groups. The Wilcoxon two sample test was employed to evaluate percent differences in bacterial microbiota, percent $\mathrm{CD}^{+}$and $\mathrm{CD}^{+}$spleen cells, max clinical scores, and area under the curve (sum clinical scores) between groups. Statistical significance was set at $\mathrm{p} \leq 0.05$ for both the Student's t-test and the Wilcoxon two sample test. For regression analysis between clinical score and rotarod latency, the $r^{2}$ value and statistical significance $(\mathrm{p} \leq 0.05)$ were evaluated using GraphPad Prism 6 software (GraphPad Software, Inc., San Diego, CA).

\section{Results}

Omeprazole affects the gut microbiota in C57BL/6J mice with EAE

The gut microflora has been shown to affect EAE disease progression [4-6]. Since omeprazole can elevate the gastric $\mathrm{pH}$ [16], which could affect the growth of populations of bacteria in the gut [17], omeprazole has the potential to affect the progression of EAE. We first sought to determine the effect of chronic omeprazole treatment on the bacterial gut microbiota in C57BL/6J mice with EAE. Shifts in percentages of specific bacteria populations were identified following omeprazole treatment (Figure 1A, B); in particular, there were significant decreases in Akkermansia muciniphila and Coprococcus sp. and an increase in unidentified microbes in the family S24-7 (order Bacteroidales), which was the most abundant OTU in the fecal samples (Figure 1C-E; Additional file 1: Table S1). There were numerous different bacterial taxa detected (Figure 1A, B; Additional file 1: Table S1), but there was no significant difference in their relative abundance between the omeprazole and saline EAE mice, or they represented $<0.1 \%$ of the total bacterial population.

\section{Omeprazole does not affect spleen T cell content in C57BL/6J mice with EAE}

Since the spleen is a key site of $\mathrm{T}$ cell activation and has a prominent role in the development of EAE [18], the effect of omeprazole on spleen $\mathrm{T}$ cell populations was examined. T cells collected at an early clinical stage (Day 18) or during an active disease stage (Day 46) displayed no differences between omeprazole and vehicle administration (Figure 2A-D). However, there was a difference in the spleen immune cell populations between these different stages of disease progression. There were statistically significant higher numbers of EM CD4 ${ }^{+}$ T cells, CM CD4 ${ }^{+} \mathrm{T}$ cells, EM CD8 ${ }^{+} \mathrm{T}$ cells, and $\mathrm{CM}$ $\mathrm{CD}^{+} \mathrm{T}$ cells, and lower numbers of naïve $\mathrm{CD} 4^{+} \mathrm{T}$ cell and
$\mathrm{CD}^{+} \mathrm{T}$ cells in the advanced disease stage compared to the early clinical stage (Additional file 2: Figure S1A).

\section{Omeprazole does not affect clinical or pathological signs in $\mathrm{C} 57 \mathrm{BL} / 6 \mathrm{~J}$ mice with $\mathrm{EAE}$}

The first detection of EAE disease activity in most C57BL/6J mice was approximately 18 days or greater post-encephalitogen injection, about the time at which they were $\sim 7 \frac{1}{2}$ weeks old, although occasionally a low percentage of mice became sick earlier. This delayed onset compared to other studies was likely due to injection of the encephalitogen into $\sim 5$ week old C57BL/6J mice rather than older $\mathrm{C} 57 \mathrm{BL} / 6 \mathrm{~J}$ mice used in other studies $[6,19]$. After disease onset, the progression of clinical scores appeared to advance more rapidly in the EAE mice administered omeprazole compared to saline, but the differences did not achieve significance (Figure 3A). However, the differences in weight were significant (less weight gain) in the omeprazole group vs. the saline group (Figure 3B). No differences were observed in rotarod latency between groups receiving omeprazole and saline administration during any stage of EAE disease progression (Day 14, 25 or 40 post-encephalitogen injection) (Figure 3C-E), and thus, data were pooled for comparisons of rotarod latency and clinical scores. Comparison of the relationship between rotarod latency and clinical scores revealed that at Day 14 and Day 25 the two clinical measures did not correlate well (Figure 3C, D); but by Day 40, there was a strong correlation between rotarod latency and clinical scores $\left(\mathrm{r}^{2}=0.747, \mathrm{p}<0.005\right.$; Figure $3 \mathrm{E})$. Inflammatory cell infiltrates were present in the hindbrains of both omeprazole and saline treated mice during active disease, but there was no major difference between treatment groups (Figure 3F, G).

\section{Omeprazole does not affect EAE disease activity in SJL/J mice} On average, EAE in SJL/J mice was first detected by $~ 10$ days post-encephalitogen. Administration of omeprazole or saline was started at the initiation of clinical signs (Day 0 of treatment). Examination of the immune cell content in spleens during active disease revealed that administration of omeprazole did not alter the $\mathrm{T}$ cell content compared to saline (Figure 4A, B). Furthermore, there was no difference in the clinical disease profile between omeprazole and saline administered mice with EAE, i.e., both groups developed advanced disease (e.g., clinical score of 6 or 7 and substantial weight loss) which was followed by remission (e.g., clinical scores dropping to $\sim 2$ associated with weight gain) (Figure 4C, D). There was also no significant difference in rotarod behavior between mice administered omeprazole or saline during active disease or remission (Figure 4E, F), and thus the data were pooled between groups for comparisons of rotarod latency and 

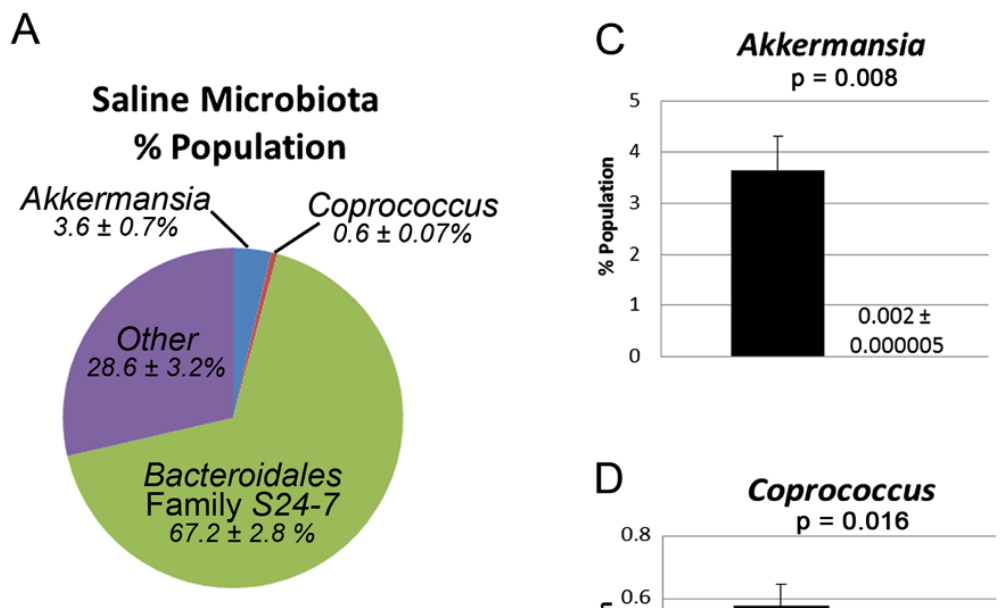

B
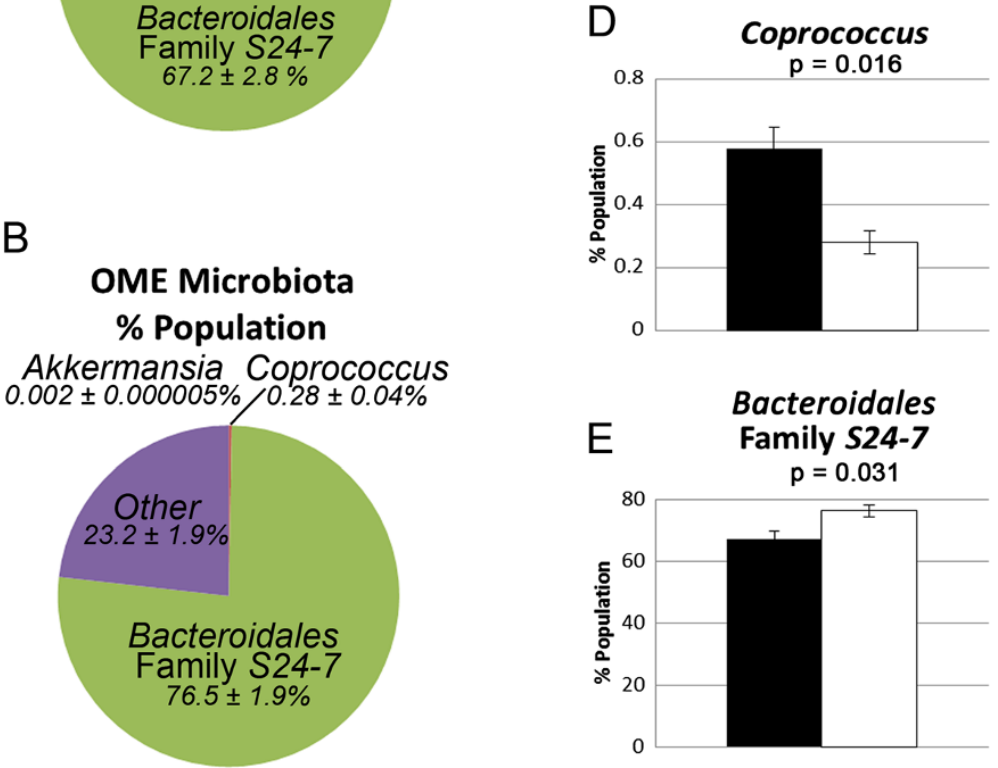

Figure 1 Next-generation sequencing of fecal microbiota from omeprazole and saline treated C57BL/6J mice. Pellets were collected on Day 40 post-encephalitogen during active disease from a subset of omeprazole $(n=5)$ and saline $(n=5)$ treated C57BL/6J mice. Sequences were annotated against a database of known 165 rRNA gene sequences and binned at all taxonomic levels (phylum, class, order, etc.). Operational taxonomic units (OTUs) represented in these graphs were statistically different following omeprazole treatment in C57BL/6J mice. Overall distribution in saline (A) and omeprazole (B) treated mice and more detailed analyses of three different OTUs (C-E) are shown. Black bars - saline treatment; white bars - omeprazole treatment. Additional information is provided in Additional file 1: Table S1.

clinical scores. There was a strong correlation between clinical score and rotarod latency during active disease $\left(\mathrm{r}^{2}=0.653, \mathrm{p}<0.005\right.$; Figure $\left.4 \mathrm{E}\right)$, but not during remission (Figure 4F) in SJL/J mice, at which point a heterogeneity in rotarod latency was revealed despite most mice displaying a similar clinical score of 2 (Figure 4F). Both omeprazole and saline treated EAE mice displayed an abundance of inflammatory cell infiltrates in the hindbrain (data not shown).

Comparisons of the spleen $\mathrm{T}$ cell content between the two strains of mice with active EAE revealed that total and naïve $\mathrm{CD}^{+}{ }^{+}$and $\mathrm{CD} 8^{+}$cells were significantly higher in $\mathrm{SJL} / \mathrm{J}$ mice than in $\mathrm{C} 57 \mathrm{BL} / 6 \mathrm{~J}$ mice, and there were more $\mathrm{CM} \mathrm{CD}^{+}$and $\mathrm{CD}^{+} \mathrm{T}$ cells in the C57BL/6J EAE mice compared to SJL/J EAE mice (Additional file 2: Figure S1B).

\section{Discussion}

The gut microflora can affect EAE disease progression [4-6]. For instance, segmented filamentous bacteria [6], likely from the genus Clostridium [20], were found to augment EAE while Bacteroides fragilis limits EAE development [21]; and depending on the species of Lactobacillus, EAE disease activity can be increased [22] or ameliorated [23]. In our study, Clostridium was not significantly different between treatments $(0.18 \pm 0.13$ saline; $0.22 \pm 0.11$ omeprazole), and Bacteroides fragilis and Lactobacillus sp. were below $0.1 \%$ in both groups (saline or omeprazole) of EAE mice. Thus, omeprazole treatment did not appear to substantially affect gut bacteria currently known to influence EAE development.

Akkermansia muciniphila was significantly lower in the omeprazole treated EAE mice compared to vehicle 

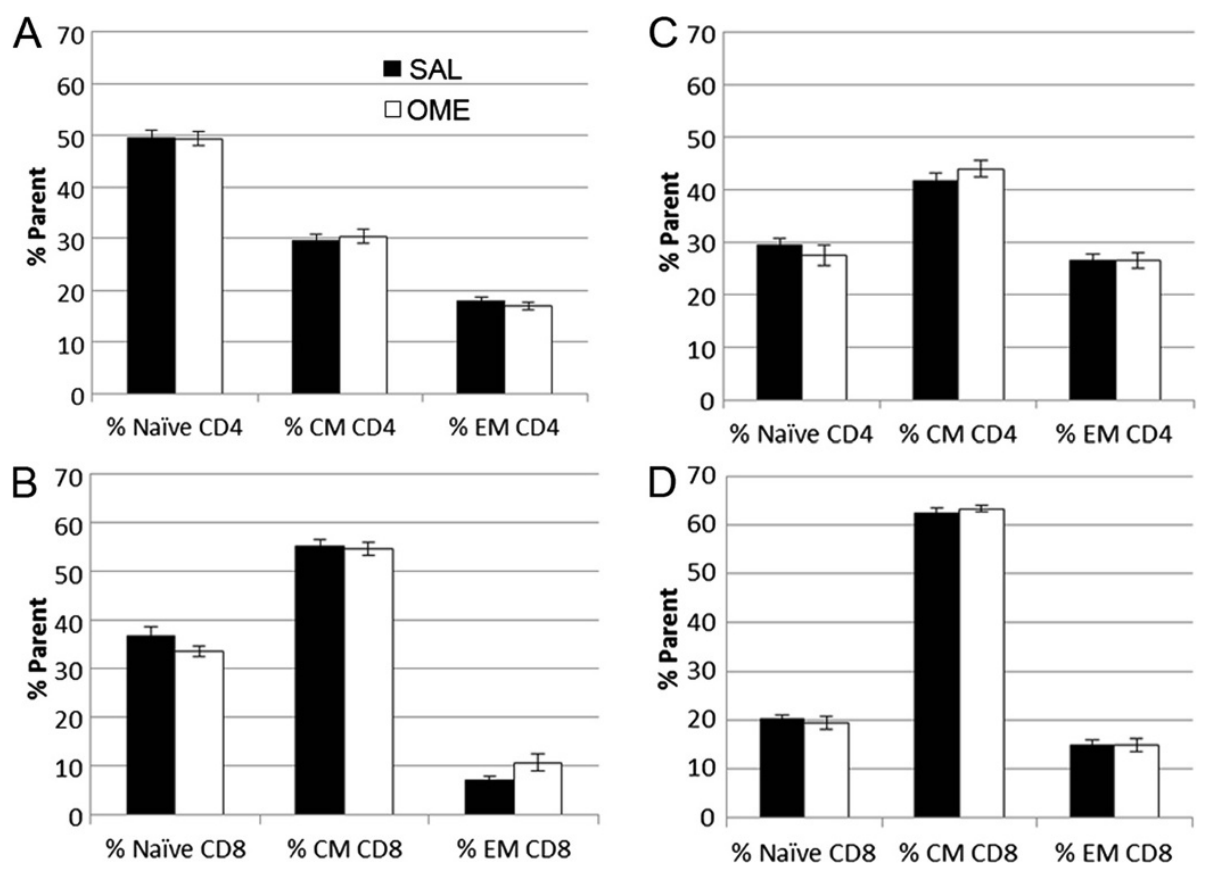

Figure 2 Evaluation of spleen immune cell content in omeprazole and saline treated C57BL/6J mice. Quantitation of spleen immune cells from flow cytometry analysis in saline and omeprazole treated C57BL/6J mice was performed on Day 18 post-encephalitogen (A, B), which was at an early clinical stage (clinical scores: saline $2.36+/-0.84, n=7$ vs. omeprazole 1.21. + /- $0.15, n=7 ; p=0.15$ ) and Day 46 post-encephalitogen (C, D), which was during an advanced disease stage (clinical scores: saline $4.14+/-0.7, n=7$ vs. omeprazole $4.14+/-0.14, n=7 ; p=1.0$ ). No differences in the percent of naïve (CD44 $\left.{ }^{\mathrm{lo}} \mathrm{CD} 62 \mathrm{~L}^{\mathrm{hi}}\right), \mathrm{CM}\left(\mathrm{CD} 44^{\mathrm{hi}} \mathrm{CD} 62 \mathrm{~L}^{\mathrm{hi}}\right.$ ) or EM (CD44 $\left.{ }^{\mathrm{hi}} \mathrm{CD} 62 \mathrm{~L}^{\mathrm{lo}}\right) \mathrm{CD} 4+$ or CD8+ cells (from parent CD4+ or CD8+ populations) were observed following omeprazole treatment vs. saline during both stages of EAE. Black bars, saline treatment; white bars, omeprazole treatment.

treated EAE mice. Akkermansia muciniphila is a mucolytic bacterium that is found in the mucus layer of the large intestine [24]. Omeprazole has been shown to inhibit mucin production by the stomach $[25,26]$. Thus, a lower production of mucins following omeprazole treatment likely made it difficult for Akkermansia muciniphila to thrive, which could account for the significantly diminished levels of Akkermansia muciniphila following omeprazole treatment. Low levels of Akkermansia muciniphila have been associated with obesity and type 2 diabetes in C57BL/6J mice [27]. However, in the present study, EAE mice given omeprazole had less weight gain, despite a lower percentage of Akkermansia muciniphila, compared to EAE mice given saline. The findings with the unidentified OTU in order Bacteroidales, family S24-7 might better explain the weight changes.

The relative abundance of this OTU (order Bacteroidales, family S24-7) increased in the present study following omeprazole treatment. An increased level of this taxon has been observed following exercise [28] and in lean mice compared to obese mice [29]. Our study did not measure absolute levels of bacteria, but rather evaluated the relative abundance of different types of bacteria. However, bacterial overgrowth can occur in the stomach and duodenum following omeprazole treatment [17], and bacterial growth and gastric acid suppressors have both been associated with weight loss in the elderly [30]. Thus, it may not be surprising that omeprazole treated EAE mice had less weight gain than saline treated EAE mice.

The percentage of Coprococcus sp. decreased following omeprazole treatment. Little is known about the genus Coprococcus relative to EAE. Its abundance is increased in Crohn's disease [31] and is decreased following exposure to social disruption stress [32] or in HIV individuals not taking combination anti-retroviral therapy [33].

Besides affecting the gut microbiota, PPIs have been shown to affect neutrophil function, which recently has been implicated to play a role in disease initiation in EAE $[34,35]$. In particular, omeprazole can decrease the migration, bactericidal activity, and oxygen-derived free radical production by neutrophils [36-38]. PPIs can also affect NK cells [39] and monocytes [40]. However, MS and EAE are primarily $\mathrm{T}$ cell driven diseases [41-47]. It is unknown whether omeprazole directly affects $\mathrm{T}$ cells, but the PPI esomeprazole was thought to create a microenvironment, via a change in $\mathrm{pH}$, more suitable for $\mathrm{T}$ cell activity against tumors [48]. In the present study, 

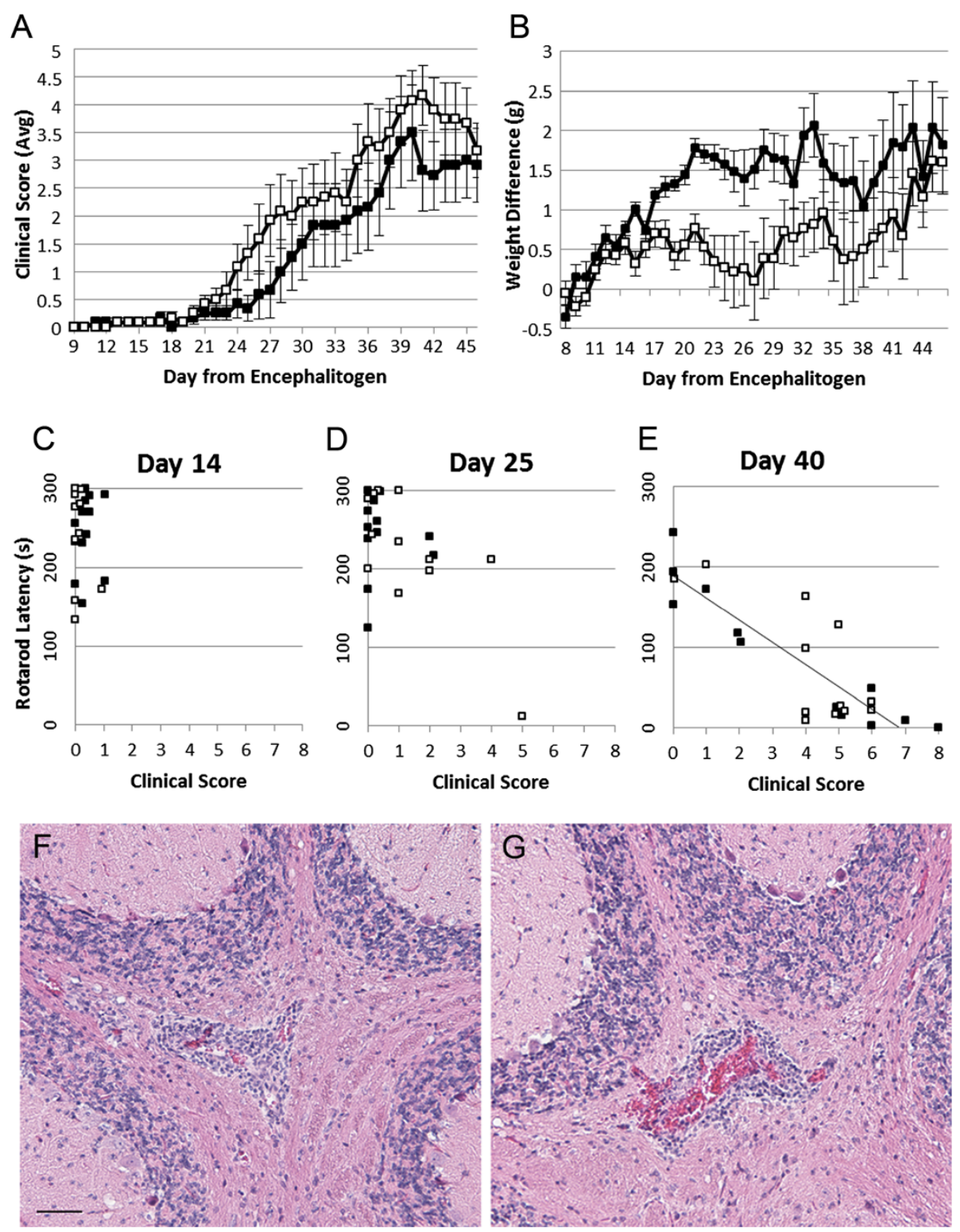

Figure 3 Comparison of omeprazole and saline treated C57BL/6J mice with EAE. Average clinical scores (A) revealed no significant differences between groups, but weight differences $(\mathbf{B})$ revealed that omeprazole treated EAE mice $(n=12)$ had significantly less weight gain relative to Day 7 than saline EAE mice $(n=12)$. Rotarod latency at Day $14(\mathbf{C})$, Day 25 (D), and Day $40(\mathbf{E})$ post-encephalitogen, with no differences observed between omeprazole and saline groups. A strong negative correlation was observed between clinical score and rotarod latency during active disease at Day 40 post-encephalitogen $\left(r^{2}=-0.747, p<0.005\right)$, but not at Day 14 or Day 25. Black squares, saline treatment; white squares, omeprazole treatment. Histological examination revealed no major differences in inflammatory cell infiltrates in the hindbrains of both saline (F) and omeprazole (G) C57BL/6J mice during active disease. Bar $=50 \mu \mathrm{m}$.

omeprazole treatment did not affect levels of different subsets of $\mathrm{T}$ cells (e.g., CM, EM) in the spleen of C57BL/6J or SJL/J EAE mice. Furthermore, omeprazole did not affect relative levels of inflammatory cell infiltrates in the hindbrain, which are largely composed of $\mathrm{T}$ cells, in either strain, although it is possible that omeprazole could affect other components of the $\mathrm{T}$ cell response.
Aside from differences in weight gain in C57BL/6J EAE mice, omeprazole did not affect other clinical measures of disease activity, i.e., clinical scores and rotarod latency, in either C57BL/6J or SJL/J EAE mice. Independent of treatment, rotarod latency did not appear to correlate with clinical scores during the preclinical or early stage of EAE in C57BL/6J mice, but a strong correlation was present in animals with active disease, and 


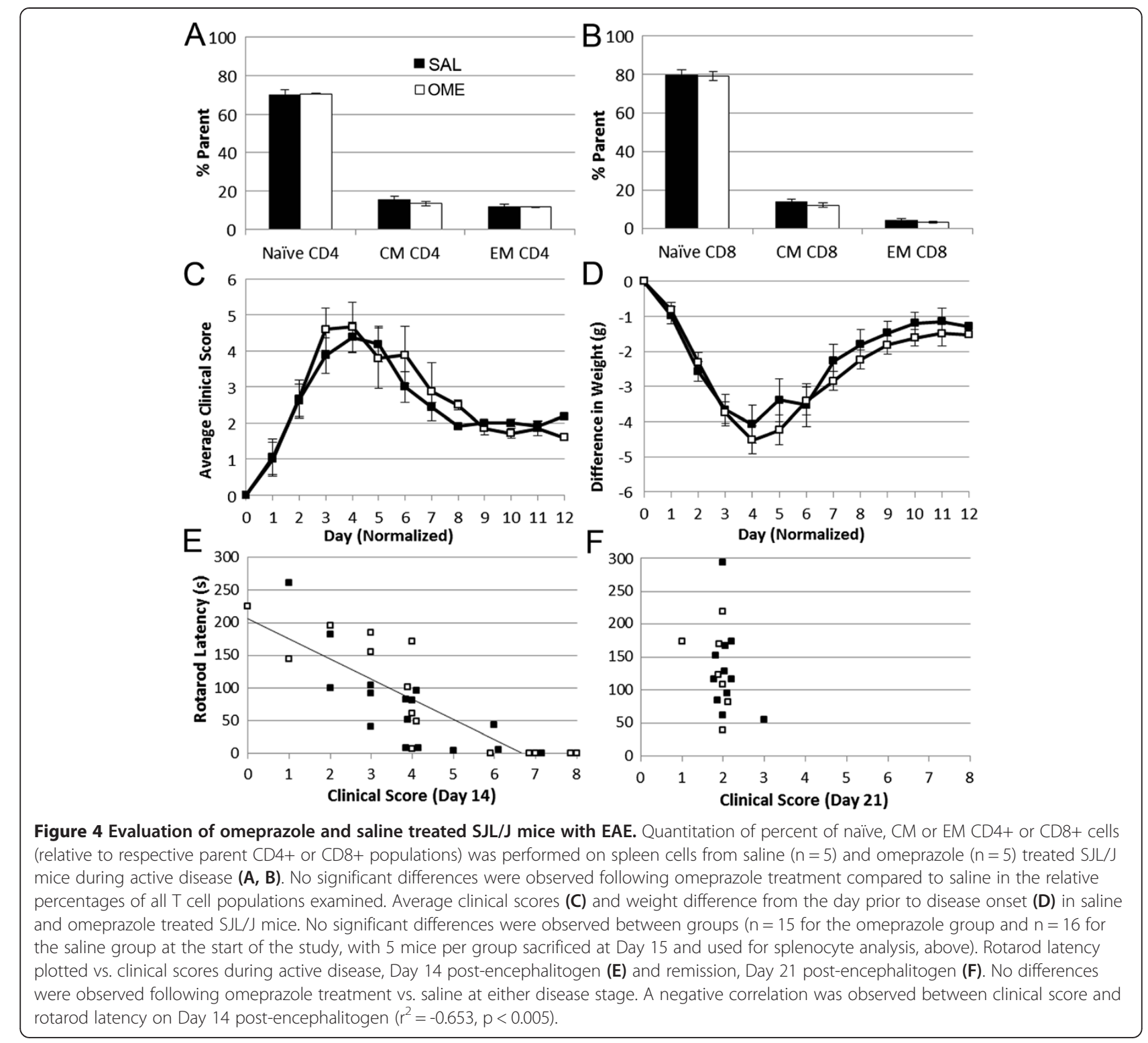

this correlation was also observed for SJL/J mice with active disease. However, once the SJL/J mice entered into remission, based on clinical signs, the correlation was lost. For example, almost all the SJL/J mice had a clinical score of 2 during remission, yet there was a wide heterogeneity in rotarod latency values which did not appear to correlate to a prior maximum clinical score or with hindbrain pathology (i.e., inflammatory cell infiltrates). Thus, rotarod testing revealed that mice in remission had a range of persistent deficiencies that were not reflected in the clinical score. Therefore, we suggest that rotarod latency can be a useful measure to complement clinical scoring for disease assessment, particularly during later stages of disease. Interestingly, the expanded disability status scale has quantitative measures of mobility included in the evaluation of disease status in MS patients [49]; thus, including both clinical scores and rotarod latency for measurement of EAE activity would more closely align the evaluations used for human and rodent studies.

Th1 $\mathrm{CD}^{+}, \mathrm{CD}^{+}$and/or Th17 $\mathrm{T}$ cells are important contributors to disease activity in EAE and MS [41-47]. The spleen $\mathrm{T}$ cell population changed during different stages of disease in C57BL/6J mice. A decrease of naïve $\mathrm{CD}^{+}$and $\mathrm{CD}^{+}$cells was associated with an increase in both $\mathrm{EM}$ and $\mathrm{CM} \mathrm{CD} 4^{+}$and $\mathrm{CD} 8^{+}$cells during active disease compared to early disease. Furthermore, the total number of $\mathrm{CD}^{+}$and $\mathrm{CD} 8^{+}$spleen cells were increased during active disease. These changes likely reflect the heightened activation of the immune system during active 
disease and support the finding that effector and memory T cells affect the development of EAE [50].

During active disease, a higher percentage of naïve $\mathrm{CD}_{4}^{+}$and $\mathrm{CD}^{+}{ }^{+}$and a lower percentage of $\mathrm{CM} \mathrm{CD} 4^{+}$ and $\mathrm{CD}^{+}$cells and $\mathrm{EM} \mathrm{CD} 8^{+}$cells were observed in SJL/J mice compared to C57BL/6J mice. There was also a difference in the absolute cell counts in the spleen of the two strains, with SJL/J having nearly twice as many cells as the C57BL/6J. These differences are likely accounted for by apoptosis and spleen atrophy, which have been observed in spleens of mice with progressive EAE, but not with relapsing-remitting EAE [51].

An observation during the procedures used for this study was that defecation appeared less frequent in EAE mice with advanced disease compared to healthier mice, regardless of treatment. This may have been due to a difference in food consumption or a disruption of nervous control over peristalsis and/or defecation as EAE progressed; of note, bowel dysfunction occurs in a large percentage of MS patients, which can be due to a variety of causes [52].

\section{Conclusions}

Although there was a difference in the microbiota and weight gain in the C57BL/6J EAE model, omeprazole had no effect on spleen $\mathrm{T}$ cell populations, clinical scores, rotarod, and histopathology in C57BL/6J and SJL/J EAE mice. Thus, omeprazole does not appear to have a positive or negative effect on the disease course of EAE, suggesting that omeprazole may not be affecting disease activity in MS patients. However, despite testing in two EAE models, the design used in the present study has limitations relative to applicability to humans. Besides the obvious limitation of extrapolating results from mice with EAE to humans with MS, the gut microbiota in each individual is a result of multiple factors; thus, it is theoretically possible that in specific situations a PPI could cause a shift in the microbiota, or other factor, that influences MS disease activity. As we learn more about the influences of the gut microflora on MS disease activity, it might become relevant to revisit the role of PPIs in MS.

\section{Additional files}

\section{Additional file 1: Table S1. Operational taxonomic units.}

Additional file 2: Figure S1. Since there were no clear differences between saline and omeprazole treatment in the percent of naïve, CM or EM CD4+ or CD8+ cells (from parent CD4+ or CD8+ populations)

(Figure 2), mice from the omeprazole and saline groups were pooled and used to analyze the differences in immune cell populations between the two different stages of EAE in C57BL/6J mice (clinical scores at Day $18 \mathrm{vs.}$ Day $46, p=0.0009$ ) using absolute numbers of the total spleen cell population (A). More CM and EM CD4+ and CD8+ were observed at the advanced disease stage and more naïve CD4+ and CD8+ cells were observed during the early clinical stage $\left(^{*} p<0.05\right.$; ${ }^{* *} p<0.001$; $\left.{ }^{* * *} p<0.00001\right)$. Comparison of spleen cells from SJL/J mice with active disease (Day 15) and C57BL/6J mice with active disease (Day 46) (B). Since there were no clear differences between saline and omeprazole treatment, mice from the omeprazole and saline groups were pooled to analyze the differences in immune cell populations between the two different strains of EAE using absolute numbers of the total spleen cell population. More CM and EM CD8+ cells and more CM CD4+ cells were observed in C57BL/6J mice compared to $\mathrm{SJ} / \mathrm{J}$ mice with active disease $\left({ }^{*} p<0.01 ;{ }^{* *} p<0.000001\right)$. Conversely, fewer total and naïve CD4+ and CD8+ cells were observed in C57BL/6J mice compared to SJL/J mice with active disease $\left({ }^{* *} p<0.000001\right)$. Black bars or squares, saline treatment; white bars or squares, omeprazole treatment.

\section{Abbreviations}

CM: Central memory; EAE: Experimental autoimmune encephalomyelitis; EM: Effector memory; i.p.: Intraperitoneal; MS: Multiple sclerosis; OTUs: Operational taxonomic units; PTX: Pertussis toxin; PPI: Proton pump inhibitors.

\section{Competing interests}

SML has received an honorarium, past and current grant support and payment for travel from ApoPharma, Inc. All other authors declare that they have no competing interest.

\section{Authors' contributions}

Designed and/or carried out experiments: SAS, ST, TMY, BLP, ACE, SML. Interpreted data: SAS, ST, TMY, ACE, SML. Wrote manuscript and/or prepared figures: SAS, ST, SML. All authors read/edited a draft of the manuscript and read and approved the final manuscript.

\section{Acknowledgements}

This work was supported by the National Multiple Sclerosis Society (NMSS), $\mathrm{NIH}$ U42 OD010918 (MU Mutant Mouse Regional Resource Center), a NICHD Center Grant (HD 02528), and the Flow Cytometry Core Laboratory, which is sponsored, in part, by the NIH/NIGMS COBRE grant P30 GM103326 and a Lied grant. The contents are solely the responsibility of the authors and do not necessarily represent the official views of any of the funding agencies listed above.

\section{Author details}

${ }^{1}$ Department of Molecular and Integrative Physiology, University of Kansas Medical Center, 3901 Rainbow Blvd, Kansas City 66160, KS, USA. ²Department of Microbiology, Molecular Genetics and Immunology, University of Kansas Medical Center, 3901 Rainbow Blvd, 66160 Kansas City, KS, USA. 르epartment of Veterinary Pathobiology, Mutant Mouse Regional Resource Center, University of Missouri, 4011 Discovery Drive, 65201 Columbia, MO, USA.

Received: 25 August 2014 Accepted: 29 August 2014

Published: 4 September 2014

\section{References}

1. Levinthal DJ, Rahman A, Nusrat S, O'Leary M, Heyman R, Bielefeldt K: Adding to the burden: gastrointestinal symptoms and syndromes in multiple sclerosis. Mult Scl Int 2013, 2013:319201.

2. Compare D, Pica L, Rocco A, De Giorgi F, Cuomo R, Sarnelli G, Romano M, Nardone G: Effects of long-term PPI treatment on producing bowel symptoms and SIBO. Eur J Clin Invest 2011, 41:380-386.

3. Canani RB, Terrin G: Gastric acidity inhibitors and the risk of intestinal infections. Curr Opin Gastroenterol 2010, 26:31-35.

4. Yokote H, Miyake S, Croxford JL, Oki S, Mizusawa H, Yamamura T: NKT celldependent amelioration of a mouse model of multiple sclerosis by altering gut flora. Am J Pathol 2008, 173:1714-1723.

5. Ochoa-Repáraz J, Mielcarz DW, Ditrio LE, Burroughs AR, Foureau DM, Haque-Begum S, Kasper LH: Role of gut commensal microflora in the development of experimental autoimmune encephalomyelitis. J Immunol 2009, 183:6041-6050.

6. Lee YK, Menezes JS, Umesaki Y, Mazmanian SK: Proinflammatory T-cell responses to gut microbiota promote experimental autoimmune encephalomyelitis. Proc Natl Acad Sci 2011, 108(Suppl 1):4615-4622. 
7. Biswas S, Benedict SH, Lynch SG, LeVine SM: Potential immunological consequences of pharmacological suppression of gastric acid production in patients with multiple sclerosis. BMC Med 2012, 10:57

8. Mitchell KM, Dotson AL, Cool KM, Chakrabarty A, Benedict SH, LeVine SM: Deferiprone, an orally deliverable iron chelator, ameliorates experimental autoimmune encephalomyelitis. Mult Scler 2007 13:1118-1126.

9. Caporaso JG, Lauber CL, Walters WA, Berg-Lyons D, Lozupone CA Turnbaugh PJ, Fierer N, Knight R: Global patterns of 16S rRNA diversity at a depth of millions of sequences per sample. Proc Natl Acad Sci 2011, 108(Suppl 1):4516-4522.

10. Walters WA, Caporaso JG, Lauber CL, Berg-Lyons D, Fierer N, Knight R: PrimerProspector: de novo design and taxonomic analysis of barcoded polymerase chain reaction primers. Bioinformatics 2011, 27:1159-1161.

11. Loy A, Maixner F, Wagner M, Horn M: probeBase-an online resource for rRNA-targeted oligonucleotide probes: new features 2007. Nucleic Acids Res 2007, 35:D800-804.

12. Magoč T, Salzberg SL: FLASH: fast length adjustment of short reads to improve genome assemblies. Bioinformatics 2011, 27:2957-2963.

13. Kuczynski J, Stombaugh J, Walters WA, González A, Caporaso JG, Knight R: Using QIIME to analyze 16S rRNA gene sequences from microbial communities. Curr Protoc Bioinformatics 2011, 36:10.7:10.7.1-10.7.20.

14. Altschul SF, Madden TL, Schäffer AA, Zhang J, Zhang Z, Miller W, Lipman DJ: Gapped BLAST and PSI-BLAST: a new generation of protein database search programs. Nucleic Acids Res 1997, 25:3389-3402.

15. DeSantis TZ, Hugenholtz P, Larsen N, Rojas M, Brodie EL, Keller K, Huber T, Dalevi D, Hu P, Andersen GL: Greengenes, a chimera-checked 16S rRNA gene database and workbench compatible with ARB. Appl Environ Microbiol 2006, 72:5069-5072

16. Atanassoff PG, Brull SJ, Weiss BM, Landefeld K, Alon E, Rohling R: The time course of gastric $\mathrm{pH}$ changes induced by omeprazole and ranitidine: a 24-hour dose-response study. Anesth Analg 1995, 80:975-979.

17. Thorens J, Froehlich F, Schwizer W, Saraga E, Bille J, Gyr K, Duroux P, Nicolet M, Pignatelli B, Blum AL, Gonvers JJ, Fried M: Bacterial overgrowth during treatment with omeprazole compared with cimetidine: a prospective randomized double blind study. Gut 1996, 39:54-59.

18. Rigolio R, Biffi A, Oggioni N, Cavaletti G: Actively induced EAE in Lewis rats: characterization of spleen and spinal cord infiltrating lymphocytes by flow cytometry during the course of the disease. J Neuroimmunol 2008, 199:67-74

19. Cravens PD, Kieseier BC, Hussein R, Herndon E, Arellano B, Ben LH, Timmons BC, Castro-Rojas C, Hartung HP, Hemmer B, Weber MS, Zamvil SS, Stüve O: The neonatal CNS is not conducive for encephalitogenic Th1 T cells and B cells during experimental autoimmune encephalomyelitis. J Neuroinflamm 2013, 10:67.

20. Ivanov II, Atarashi K, Manel N, Brodie EL, Shima T, Karaoz U, Wei D, Goldfarb KC, Santee CA, Lynch SV, Tanoue T, Imaoka A, Itoh K, Takeda K, Umesaki Y, Honda K, Littman DR: Induction of intestinal Th17 cells by segmental filamentous bacteria. Cell 2009, 139:485-498.

21. Ochoa-Repáraz J, Mielcarz DW, Ditrio LE, Burroughs AR, Begum-Haque S, Dasgupta S, Kasper DL, Kasper LH: Central nervous system demyelinating disease protection by the human commensal Bacteroides fragilis depends on polysaccharide A expression. J Immunol 2010, 185:4101-4108.

22. Baken KA, Ezendam J, Gremmer ER, de Klerk A, Pennings JLA, Matthee B, Peijnenburg AACM, van Loveren $\mathrm{H}$ : Evaluation of immunomodulation by Lactobacillus casei Shirota: immune function, autoimmunity and gene expression. Int J Food Microbiol 2006, 112:8-18.

23. Lavasani S, Dzhambazov B, Nouri M, Fåk F, Buske S, Molin G, Thorlacius H, Alenfall J, Jeppsson B, Weström B: A novel probiotic mixture exerts a therapeutic effect on experimental autoimmune encephalomyelitis mediated by IL-10 producing regulatory T cells. PLoS One 2010, 5:e9009.

24. Derrien M, Vaughan EE, Plugge CM, de Vos WM: Akkermansia muciniphila gen. nov., sp. nov., a human intestinal mucin-degrading bacterium. Int Syst Evol Microbiol 2004, 54:1469-1476.

25. Matsumoto A, Asada S, Okumura Y, Takiuchi H, Hirata I, Ohshiba S: Effects of anti-acid secretory agents on various types of gastric mucus. J Clin Gastroenterol 1992, 14(Suppl 1):S94-97.

26. Yoshimura K, Delbarre SG, Kraus E, Boland CR: The effects of omeprazole and famotidine on mucin and $\mathrm{PGE}_{2}$ release in the rat stomach. Aliment Pharmacol Ther 1996, 10:111-117.
27. Everard A, Belzer C, Geurts L, Ouwerkerk JP, Druart C, Bindels LB, Guiot $Y$, Derrien M, Muccioli GG, Delzenne NM, de Vos WM, Cani PD: Cross-talk between Akkermansia muciniphila and intestinal epithelium controls diet-induced obesity. Proc Natl Acad Sci 2013, 110:9066-9071.

28. Evans CC, LePard KJ, Kwak JW, Stancukas MC, Laskowski S, Dougherty J, Moulton L, Glawe A, Wang Y, Leone V, Antonopoulos DA, Smith D, Chang EB, Ciancio MJ: Exercise prevents weight gain and alters the gut microbiota in a mouse model of high fat diet-induced obesity. PLoS One 2014, 9:e92193.

29. Turnbaugh PJ, Ley RE, Mahowald MA, Magrini V, Mardis ER, Gordon Jl: An obesity-associated gut microbiome with increased capacity for energy harvest. Nature 2006, 444:1027-1031.

30. Parlesak A, Klein B, Schecher K, Bode JC, Bode C: Prevalence of small bowel bacterial overgrowth and its association with nutrition intake in nonhospitalized older adults. J Am Geriatr Soc 2003, 51:768-773.

31. Ruseler-van Embden JG, van Lieshout LM: Increased faecal glycosidases in patients with Crohn's disease. Digestion 1987, 37:43-50.

32. Bailey MT, Dowd SE, Galley JD, Hufnagle AR, Allen RG, Lyte M: Exposure to a social stressor alters the structure of the intestinal microbiota: implications for stressor-induced immunomodulation. Brain Behav Immun 2011, 25:397-407.

33. McHardy $H_{\text {, }}$ Li X, Tong M, Ruegger P, Jacobs J, Borneman J, Anton P, Braun J: HIV Infection is associated with compositional and functional shifts in the rectal mucosal microbiota. Microbiome 2013, 1:26.

34. Christy AL, Walker ME, Hessner MJ, Brown MA: Mast cell activation and neutrophil recruitment promotes early and robust inflammation in the meninges in EAE. J Autoimmun 2013, 42:50-61.

35. Wojkowska DW, Szpakowski P, Ksiazek-Winiarek D, Leszczynski M, Glabinski A: Interactions between neutrophils, Th17 cells, and chemokines during the initiation of experimental model of multiple sclerosis. Mediators Inflamm 2014, 2014:590409.

36. Suzuki M, Mori M, Miura S, Suematsu M, Fukumura D, Kimura $H$, Ishii $H$ : Omeprazole attenuates oxygen-derived free radical production from human neutrophils. Free Rad Biol Med 1996, 21:727-731.

37. Zedtwitz-Liebenstein K, Wenisch C, Patruta S, Parschalk B, Daxböck F, Graninger W: Omeprazole treatment diminishes intra- and extracellular neutrophil reactive oxygen production and bactericidal activity. Crit Care Med 2002, 30:1118-1122.

38. Martins de Oliveira R, Antunes E, Pedrazzoli J Jr, Gambero A: The inhibitory effects of $\mathrm{H}^{+} \mathrm{K}^{+}$ATPase inhibitors on human neutrophils in vitro: restoration by a $\mathrm{K}^{+}$ionophore. Inflamm Res 2007, 56:105-111.

39. Alkim H, Unal $\mathrm{S}$, Okur H, Imir T: Omeprazole inhibits natural killer cell functions. Dig Dis Sci 2008, 53:347-351.

40. Ohara T, Arakawa T: Lansoprazole decreases peripheral blood monocytes and intracellular adhesion molecule-1-positive mononuclear cells. Dig Dis Sci 1999, 44:1710-1715.

41. Huseby ES, Liggitt D, Brabb T, Schnabel B, Öhlén C, Goverman J: A pathogenic role for myelin-specific $C D 8^{+} T$ cells in a model for multiple sclerosis. J Exp Med 2001, 194:669-676.

42. Sun D, Whitaker JN, Huang Z, Liu D, Coleclough C, Wekerle H, Raine CS: Myelin antigen-specific CD8 ${ }^{+} \mathrm{T}$ cells are encephalitogenic and produce severe disease in C57BL/6J mice. J Immunol 2001, 166:7579-7587.

43. Sonobe $Y$, Jin S, Wang J, Kawanokuchi J, Takeuchi H, Mizuno T, Suzumura A: Chronological changes of $\mathrm{CD}^{+}$and $\mathrm{CD}^{+} \mathrm{T}$ cell subsets in the experimental autoimmune encephalomyelitis, a mouse model of multiple sclerosis. Tohoku J Exp Med 2007, 213:329-339.

44. Friese MA, Fugger L: Pathogenic $\mathrm{CD}^{+} \mathrm{T}$ cells in multiple sclerosis. Ann Neurol 2009, 66:132-141.

45. Fletcher JM, Lalor SJ, Sweeney CM, Tubridy N, Mills KHG: T cells in multiple sclerosis and experimental autoimmune encephalomyelitis. Clin Exp Immunol 2010, 162:1-11.

46. Lovett-Racke AE, Yang Y, Racke MK: Th1 versus Th17: are T cell cytokines relevant in multiple sclerosis? Biochim Biophys Acta 1812, 2011:246-251.

47. Huber M, Heink S, Pagenstecher A, Reinhard K, Ritter J, Visekruna A, Guralnik A Bollig N, Jeltsch K, Heinemann C, Wittmann E, Buch T, Prazeres da Costa O, Brüstle A, Brenner D, Mak TW, Mittrücker HW, Tackenberg B, Kamradt T, Lohoff M: IL-17A secretion by CD8 ${ }^{+} \mathrm{T}$ cells supports Th17-mediated autoimmune encephalomyelitis. J Clin Invest 2013, 123:247-260.

48. Calcinotto A, Filipazzi P, Grioni M, lero M, De Milito A, Ricupito A, Cova A, Canese R, Jachetti E, Rossetti M, Huber V, Parmiani G, Generoso L, Santinami M, Borghi M, Fais S, Bellone M, Rivoltini L: Modulation of microenvironment 
acidity reverses anergy in human and murine tumor-infiltrating $T$ lymphocytes. Cancer Res 2012, 72:2746-2756.

49. Kurtzke JF: Rating neurologic impairment in multiple sclerosis: an expanded disability status scale (EDSS). Neurology 1983, 33:1444-1452

50. Elyaman W, Kivisäkk P, Reddy J, Chitnis T, Raddassi K, Imitola J, Bradshaw E, Kuchroo VK, Yagita H, Sayegh MH, Khoury SJ: Distinct functions of autoreactive memory and effector $\mathrm{CD}^{+} \mathrm{T}$ cells in experimental autoimmune encephalomyelitis. Am J Pathol 2008, 173:411-422.

51. Tsunoda I, Libbey JE, Kuang LQ, Terry EJ, Fujinami RS: Massive apoptosis in lymphoid organs in animal models for primary and secondary progressive multiple sclerosis. Am J Pathol 2005, 167:1631-1646.

52. Wiesel PH, Norton C, Glickman S, Kamm MA: Pathophysiology and management of bowel dysfunction in multiple sclerosis. Eur $J$ Gastroenterol Hepatol 2001, 13:441-448.

Cite this article as: Sands et al:: The effect of omeprazole on the

development of experimental autoimmune encephalomyelitis in C57BL/ 6J and SJL/J mice. BMC Research Notes 2014 7:605.

\section{Submit your next manuscript to BioMed Central and take full advantage of:}

- Convenient online submission

- Thorough peer review

- No space constraints or color figure charges

- Immediate publication on acceptance

- Inclusion in PubMed, CAS, Scopus and Google Scholar

- Research which is freely available for redistribution 